\title{
Clinical Characteristics of Intraoperative Cardiac Arrest During Cancer Surgery
}

\author{
Jae Hoon Lee a, Won Ho Han a, Jee Hee Kim b,* \\ ${ }^{a}$ Department of Surgery, National Cancer Center, Goyang, Korea \\ ${ }^{b}$ Department of Anesthesiology, National Cancer Center, Goyang, Korea
}

\section{Article history:}

Recevied: March 29, 2021

Revised: May 17, 2021

Accepted: May 30, 2021

\section{ABSTRACT}

Purpose: Intraoperative cardiac arrest (IOCA) is rare, unpredictable, and may result in a poor outcome. The features of IOCA during cancer surgery and factors related to survival following an IOCA were examined.

Methods: This was a retrospective study of patients who had cancer surgery under general anesthesia between March 2009 and March $2021(n=84,615)$ to determine the number of patients who had an IOCA. Patients' clinical information, cause of IOCA, hypoxemia during anesthesia, and the duration of hypotension and CPR were analyzed.

Results: A total of 22 cases of IOCA occurred during cancer surgery (overall incidence: 2.6 per 10,000 surgeries). Return of spontaneous circulation was achieved in 17 patients, but only 13 survived until discharge. There were statistically significant differences between the deceased and the survival cancer patient groups in; (1) duration of hypoxemia (survival group: 5 minutes, range: 2-18 minutes; deceased group: 60 minutes, range, 22.5-120 minutes; $p=0.019$ ); (2) duration of hypotension (survival group: 35 minutes, range, 15-55 minutes; deceased group 160 minutes, range, 140-185 minutes; $p=0.007$ ); and (3) total duration of CPR (survival group: 3 minutes, range: 1-15 minutes; deceased group: 40 minutes, range: 19-149 minutes; $p=0.005$ ).

Conclusion: The duration of hypoxemia and hypotension prior to the onset of IOCA, as well as the duration of CPR were associated with the prognosis of IOCA, highlighting the need to reduce multiorgan damage caused by hypoxemia and hypotension during surgery in high-risk patients.

Keywords: cardiac arrest, neoplasms, prognosis, surgical oncology

\author{
*Corresponding Author: \\ Department of Anesthesiology, National \\ Cancer Center, 323 Ilsan-ro, llsandong-gu, \\ Goyang 410-769, Gyeonggi, Korea \\ ORCID \\ Jae Hoon Lee \\ https://orcid.org/0000-0002-3548-9593 \\ Won Ho Han \\ https://orcid.org/0000-0002-7835-7603 \\ Jee Hee Kim \\ https://orcid.org/0000-0003-4297-7437
}

minimize the incidence of IOCA and minimize the associated sequelae $[4,5]$.

Currently, surgery is the only treatment option to achieve complete remission in some early cancers. Recently, the scope of surgical oncology has expanded, which has led to an increase in the number: (1) of extensive surgeries; (2) age at cancer diagnosis; and (3) number of surgeries performed on highrisk patients with comorbidities. Additionally, malnutrition, an immunocompromised condition, and a decrease in functional capacity, all of which are commonly observed in cancer patients, require careful consideration and attention whilst deciding on the course of anesthesia and surgery [6,7]. Considering the 
characteristics of cancer surgery, it is important to investigate the characteristics for appropriate management to reduce the sequelae of IOCA. However, previous studies have generally sought to investigate IOCA in the general population as a whole, including patients with, and without cancer [8-10].

This study retrospectively analyzed Cancer Center patients, across a period of 12 years who had an IOCA during cancer surgery, to investigate the features of IOCA and factors related to survival.

\section{Materials and Methods}

Amongst the patients who underwent cancer surgery under general anesthesia over a period of 12 years, from January 2010 to March 2021, at a single cancer center ( $n=84,615)$, those who had an IOCA were included in this study $(n=22)$. IOCA was defined as "the onset of cardiac arrest in the duration between the induction and termination of anesthesia." Cases of postoperative cardiac arrests which occurred outside the operating room, such as in the recovery room, ward, or intensive care unit were excluded from the study.

Baseline and demographic characteristics of the patients including sex, age, American Society of Anesthesiologists (ASA) score, emergency surgery, preoperative diagnosis, operation, pulmonary function, cause of cardiac arrest, preoperative electrocardiographic (ECG) abnormalities, return of spontaneous circulation (ROSC), and hospital discharge were examined. The cause of IOCA, with reference to the records of anesthesia and surgery were examined. Intraoperative characteristics, including cardiovascular disease, duration of anesthesia and surgery, blood loss, shockable rhythm, method of cardiopulmonary resuscitation (CPR) (cardiac compression, defibrillator, medication (epinephrine, atropine, phenylephrine), and duration of CPR. Cardiac arrest was defined as "a state requiring cardiopulmonary resuscitation using a defibrillator or mandatory cardiac compression, along with the administration of medication," were compared between the survival group, and the deceased group. The duration of hypoxemia was defined as "the duration of oxygen saturation $<90 \%$ on the monitor for a minimum of 5 minutes," and the duration of hypotension was defined as "the duration of mean arterial blood pressure (MAP) $<65 \mathrm{mmHg}$ on the monitor for a minimum of 5 minutes." Cardiovascular disease was defined as "coronary heart disease, arrhythmia, peripheral artery disease, or cerebrovascular disease." Pre-operative ECG abnormality was defined as "the presence of arrhythmia, including atrial fibrillation, left or right bundle branch block, left ventricular hypertrophy, and premature ventricular complexes, which had been previously reported to have prognostic significance" [11].

The survival group, and the deceased group were compared to identify the factors associated with survival until discharge. This study was approved by the Institutional Review Board of the National Cancer Center (approval no.: NCC 2021-0080).

\section{Statistical analysis}

All values are expressed as mean \pm SE of the mean or median (range). Categorical variables were compared between the survival group, and the deceased group using the Pearson $\mathrm{X} 2$ test, and continuous variables were compared between the groups using the Student $t$ test or Mann Whitney U test as appropriate. Statistical significance was set at $p<0.05$. All statistical analyses were performed using SAS Version 9.1.3 for Windows (SAS Institute, Cary, NC, USA).

\section{Results}

\section{Incidence of intraoperative cardiac arrest according to site of surgery}

IOCA occurred in 22 patients out of a total of 84,615 cases of cancer surgeries during the study period, with an overall incidence of 2.6 per 10,000 surgeries. The incidence of IOCA was the highest for cancer surgeries in the chest region (7.3 per $10,000)$, compared with all other sites of cancer surgery (Figure 1 ).



Figure 1. Incidence of intraoperative cardiac arrest according to site of surgery (X axis : Site of surgery, Y axis : Number of patients per 10,000 surgeries).

\section{Preoperative characteristics of IOCA}

The characteristics of the patients who experienced an IOCA are shown in Table 1. Eight cases were emergency surgeries (36\%). The most common cause of cardiac arrest was septic shock (27\%), followed by hemorrhage (23\%), cardiogenic (18\%), pulmonary embolism, and hypoxemia (9\%). Of the patients who experienced an IOCA, 50\% had preoperative ECG abnormalities, and $45 \%$ had cardiovascular disease. Amongst all patients, the mean duration of CPR was 8 minutes (range: 2-35 minutes), and while 17 patients achieved ROSC (77\%), 4 patients did not 
Table 1. General patients' characteristics on admission.

\begin{tabular}{|c|c|c|}
\hline & Patients $(N=22)$ & $\%$ \\
\hline \multicolumn{3}{|l|}{ Sex } \\
\hline Male & 13 & 59 \\
\hline Female & 9 & 40.9 \\
\hline Age $(y)$ & $64(56-78)$ & \\
\hline \multicolumn{3}{|l|}{ ASA score } \\
\hline 1 & 3 & 13.6 \\
\hline 2 & 8 & 36.3 \\
\hline$\geq 3$ & 11 & 50 \\
\hline Emergency surgery & 8 & 36.3 \\
\hline \multicolumn{3}{|l|}{ Cause of cardiac arrest } \\
\hline Hemorrhage & 5 & 22.7 \\
\hline Cardiogenic & 4 & 18.1 \\
\hline Pulmonary embolism & 2 & 9 \\
\hline Septic shock & 6 & 27.2 \\
\hline Hypoxemia & 2 & 9 \\
\hline Unknown & 3 & 13.6 \\
\hline Abnormal preoperative ECG & 11 & 50 \\
\hline Cardiovascular disease (angina, MI history) & 10 & 45.4 \\
\hline Shockable rhythm & 6 & 27.2 \\
\hline Duration of CPR (min) & $8(2-35)$ & \\
\hline ROSC & 17 & 77.2 \\
\hline Survival to discharge & 13 & 59 \\
\hline
\end{tabular}

ASA score = American Society of Anesthesiologists score; ECG = electrocardiography; $C P R=$ cardiopulmonary resuscitation; ROSC $=$ return of spontaneous circulation; $\mathrm{MI}=$ myocardial infarction.

survive, resulting in 13 cases of survival until discharge. In the survival group, 2 patients showed permanent neurological sequelae (comatose status and hypoxic brain injury). All emergency operations were related to cancer progression or treatment. Three patients had acute hemorrhage due to cancer progression, 2 had bowel perforation, and 2 underwent emergency surgery due to bowel ischemia, all of which were associated with cancer progression or recent chemotherapy.

\section{Comparison of pre-operative characteristics of IOCA between the survival group, and the deceased group}

There were no significant differences in age, sex, ASA score, perioperative MAP, and abnormalities in pre-operative ECG between the survival group, and the deceased group. The rate of cardiovascular disease was higher in the deceased group (55.5\%) compared with the survival group (38.4\%), but the difference was not statistically significant. Although the rate of advanced stage cancer or palliative surgery was higher in the deceased group, there was no statistical significance between groups (Table 2).

\section{Comparison of intraoperative characteristics of IOCA be- tween the survival group, and the deceased group}

Regarding the cause of IOCA, there were 4 cases of cardiogenic arrest, and all these cases were in the survival group. The cause was unknown in 1 case in the survival group and 2 cases in the deceased group. There were 5 cases of IOCA due to iatrogenic causes $(22.7 \%)$, with surgery-related hemorrhage being the most common cause ( 3 cases). Anesthesia-related IOCA occurred in 1 case due to inadvertent extubation (Table 3).

\section{Survival relating factor to discharge after IOCA}

The duration of anesthesia was relatively longer in the deceased group (205 minutes, range: 140-560 minutes) 
Table 2. Preoperative characteristics according to survival to hospital discharge after IOCA.

\begin{tabular}{|c|c|c|c|}
\hline & Survival $(N=13)(\%)$ & Deceased $(N=9)(\%)$ & $p$ \\
\hline Sex & & & 0.054 \\
\hline Male & $10(76.9)$ & $3(33.3)$ & \\
\hline Female & $3(23.1)$ & $6(66.7)$ & \\
\hline Age (y) & $65(59-76)$ & $64(52-78)$ & 0.285 \\
\hline ASA score & & & 0.448 \\
\hline 1 & $1(7.6)$ & $2(22)$ & \\
\hline 2 & $5(38.4)$ & $3(33.3)$ & \\
\hline$\geq 3$ & $7(53.8)$ & $4(44.4)$ & \\
\hline Preoperative Heart rate (/min) & $79(65-100)$ & $71(59-125)$ & 0.824 \\
\hline Preoperative MBP (mmHg) & $95(68-102)$ & $88(75-99)$ & 0.674 \\
\hline Abnormal preoperative ECG & $7(53.8)$ & $4(44.4)$ & 0.665 \\
\hline Cardiovascular disease & $5(38.4)$ & $5(55.5)$ & 0.378 \\
\hline Stage of malignancy & & & 0.155 \\
\hline Stage $1-3$ & $11(76.9)$ & $5(55.5)$ & \\
\hline Stage 4 or distant metastasis & $2(15.3)$ & $4(44.5)$ & \\
\hline Purpose of surgery & & & 0.276 \\
\hline Curative & $10(76.9)$ & $4(44.5)$ & \\
\hline Palliative & $3(23)$ & $5(55.5)$ & \\
\hline
\end{tabular}

ASA score = American Society of Anesthesiologists score; ECG = electrocardiography; MBP = mean blood pressure; IOCA = intraoperative cardiac arrest.

Table 3. Intraoperative characteristics according to survival to hospital discharge after IOCA.

\begin{tabular}{|c|c|c|c|}
\hline Site of surgery & Survival $(N=13)(\%)$ & Deceased $(N=9)(\%)$ & $p$ \\
\hline Chest & & & 0.157 \\
\hline Gastrointestinal & $5(38.4)$ & 0 & \\
\hline Hepatobiliary & $5(38.4)$ & $3(33.3)$ & \\
\hline Gynecologic & $1(7.6)$ & $3(33.3)$ & \\
\hline Neuro & 0 & $2(22.2)$ & \\
\hline Orthopedic & $1(7.6)$ & $1(11.1)$ & \\
\hline Cause of cardiac arrest & $1(7.6)$ & 0 & \\
\hline Hemorrhage & & & 0.58 \\
\hline Cardiogenic & $3(23.0)$ & $2(22.2)$ & \\
\hline Pulmonary embolism & $4(30.7)$ & 0 & \\
\hline Septic shock & $1(7.6)$ & $1(11.1)$ & \\
\hline Hypoxemia & $2(15.2)$ & $4(44.4)$ & \\
\hline Unknown & $2(15.2)$ & 0 & \\
\hline Iatrogenic cause & $1(7.6)$ & $2(22.2)$ & \\
\hline Inadvertent extubation & $4(30.7)$ & $1(11.1)$ & 0.178 \\
\hline Arrhythmia-related pericardial stimulation & 1 & 0 & \\
\hline Procedure-related hemorrhage & 1 & 0 & \\
\hline
\end{tabular}

IOCA = intraoperative cardiac arrest. 
Table 4. Factors associated with survival of IOCA.

\begin{tabular}{|c|c|c|c|}
\hline & Survival $(N=13)(\%)$ & Deceased $(N=9)(\%)$ & $p$ \\
\hline Duration of anesthesia (min) & $155(140-225)$ & $205(140-560)$ & 0.216 \\
\hline Time from anesthesia initiation to CPR (min) & $105(25-75)$ & $131(40-321)$ & 0.256 \\
\hline Duration of hypoxemia (min)* & $5(2-18)$ & $60(22.5-120)$ & 0.019 \\
\hline Duration of hypotension (min) $\dagger$ & $35(15-55)$ & $160(140-185)$ & 0.007 \\
\hline Estimated blood loss (mL) & $200(10-675)$ & $3,300(50-5,000)$ & 0.253 \\
\hline Rhythm at CPR & & & 0.178 \\
\hline Non-shockable & $11(84.6)$ & $5(55.6)$ & \\
\hline Shockable & $2(13.4)$ & $4(44.4)$ & \\
\hline Duration of CPR (min) & $3(1-15)$ & $40(19-149)$ & 0.005 \\
\hline
\end{tabular}

*Hypoxemia $($ sPO2 < 90\%).

†Hypotension (mean blood pressure $<60 \mathrm{mmHg}$ ).

$\mathrm{CPR}=$ cardiopulmonary resuscitation; IOCA = intraoperative cardiac arrest.

compared with the survival group (155 minutes, range: 140-225 minutes), but the difference was not statistically significant ( $p=$ 0.216 ). The estimated blood loss differed between the survival group (200 $\mathrm{mL}$, range: $10-675 \mathrm{~mL}$ ), and the deceased group (3,300 $\mathrm{mL}$, range: $50-5,000 \mathrm{~mL})$, but the difference was not statistically significant ( $p=0.253$ ). Differences between groups in the duration of hypoxemia [5 minutes (range: 2-18 minutes) vs. 60 minutes (22.5-120 minutes) for the survival group, and the deceased group, respectively; $p=0.019$ ], duration of hypotension [35 minutes (range: 15 - 55 minutes) vs. 160 minutes (140 185 minutes) for the survival group, and the deceased group, respectively; $p=0.007$ ], and total duration of CPR [ 3 minutes (range: 1-15 minutes) vs. 40 minutes (range: 19-149 minutes) for the survival group, and the deceased group, respectively; $p=$ 0.005] were statistically significant (Table 4).

\section{Discussion}

Surgical oncology has considerably different characteristics to consider compared with other types of surgery. Cancer patients often have malnutrition, immunosuppression, and organ failure. Moreover, stressful conditions such as anesthesia and surgery can affect the progression of cancer [6,12]. Therefore, surgeons and anesthesiologists involved in surgical oncology need to understand and assess not only the removal of the tumor, but also, perioperative and postoperative complications. Although it is essential to carry out a preoperative risk assessment regarding the administration of anesthesia, and preoperative identification of patients deemed to have a high-risk of experiencing IOCA, the incidence of IOCA is very low in non-cardiac cancer surgeries. It is also important to analyze the clinical features of IOCA as well as the prognostic factors.
The incidence of IOCA in this current study was 2.6 per 10,000 surgeries, which was lower than reported in a recent study investigating IOCA during non-cardiac surgeries (1.1-5.7 per 10,000 surgeries) [13-16]. Since this current study examined cancer surgeries conducted in a cancer center, the incidence of high-risk (cardiac, vascular surgery), and emergency surgeries, which are known risk factors of IOCA, was low; this may be the reason for the lower incidence rate in this current study compared with that reported in other studies [3,17].

In this current study, The rate of hospital discharge was $59 \%$, which was similar to hospital discharge reported in other studies (50-60\%) [2,3,15]. Factors that significantly differed between the survival group, and the deceased group were the durations of hypoxemia, hypotension, and CPR. The duration of hypoxemia is an unfavorable neurological prognostic factor which occurs as a result of brain injury. In this current study, patients with hypoxemia persisting for more than 30 minutes experienced refractory septic shock or uncontrolled massive bleeding. Despite endotracheal intubation and maintenance of oxygen supply, it is assumed that the patients did not recover from hypoxemia. It is estimated that these factors may prolong the duration of cardiac arrest and affect postoperative mortality.

In this current study, the duration of hypotension was significantly associated with surviving until discharge; previous studies have also reported that the patients who needed intraoperative continuous vasopressor infusion prior to a cardiac arrest, showed a lower survival rate [18,19]. In general, the persistence of hypotension (MAP $<65 \mathrm{mmHg}$ ) is associated with myocardial infarction, acute kidney injury, and central nervous system ischemia. The persistence of hypotension (MAP $<80 \mathrm{mmHg}$ ) for 10 minutes or longer may induce organ injury [20].

The association between the duration of CPR and survival has 
been extensively documented in relation to in-hospital or outhospital cardiac arrests. A previous study reported that a shorter duration of CPR was associated with an increased rate of survival until discharge [21]. Furthermore, the survival rate decreased with increasing duration of CPR which was due to increased rates of hypoxic-ischemic brain injury and ischemic changes in the circulatory system $[22,23]$.

In this current study, there were 5 cases of IOCA related to iatrogenic factors, including 1 case of anesthesia-related IOCA, which was a lower rate than previously reported [24]. Most anesthesia-related IOCAs are associated with airway management or medication. Pediatric patients and those with severe underlying diseases are at higher risk of anesthesiarelated IOCA, possibly due to the relatively fewer numbers of cancer surgeries performed in these patients [24,25]. There were 3 cases that were related to massive hemorrhage. Aggressive tumor resection and lymph node dissection are commonly performed during cancer surgery, and IOCAs associated with cancer surgery are more closely related to the surgical procedure itself than the anesthesia.

The current study has some limitations. This study was a single-center, single-arm study, and due to the lack of data for patients who did not experience an IOCA, we could not identify the risk factors of IOCA. Furthermore, there were limitations in the analysis of survival-related factors due to the small number of IOCA cases.

\section{Conclusion}

The occurrence of an IOCA during cancer surgery is very rare, similar to that of an IOCA during non-cardiac surgeries. The duration of hypoxemia and hypotension prior to the onset of an IOCA and the duration of CPR are associated with the prognosis of IOCA, therefore, in high-risk patients it is important to reduce multi-organ damage caused by hypoxemia and hypotension during surgery.

\section{Conflicts of Interest}

No potential conflict of interest relevant to this article was reported.

\section{Acknowledgments}

This work was supported by the National Cancer Center, Korea (NCC grant 2110630-1).

\section{Ethical Statement}

This research did not involve any human or animal experiment.

\section{References}

[1] Boba A. Improved survival after intraoperative cardiac arrest in noncardiac surgical patients. Arch Surg 1995;130(5):560.

[2] Newland MC, Ellis SJ, Lydiatt CA, Peters KR, Tinker JH, Romberger DJ, et al. Anesthetic-related cardiac arrest and its mortality: A report covering 72,959 anesthetics over 10 years from a US teaching hospital. Anesthesiology 2002;97(1):108-15.

[3] Goswami S, Brady JE, Jordan DA, Li G. Intraoperative cardiac arrests in adults undergoing noncardiac surgery: Incidence, risk factors, and survival outcome. Anesthesiology 2012;117(5):1018-26.

[4] Wijdicks EFM, Hijdra A, Young GB, Bassetti CL, Wiebe S, Quality Standards Subcommittee of the American Academy of Neurology. Practice Parameter: Prediction of outcome in comatose survivors after cardiopulmonary resuscitation (an evidence-based review): Report of the Quality Standards Subcommittee of the American Academy of Neurology. Neurology 2006;67(2):203-10.

[5] Constant AL, Montlahuc C, Grimaldi D, Pichon N, Mongardon N, Bordenave $\mathrm{L}$, et al. Predictors of functional outcome after intraoperative cardiac arrest. Anesthesiology 2014;121(3):482-91.

[6] Argilés JM. Cancer-associated malnutrition. Eur J Oncol Nurs 2005;9 Suppl 2:S39-50.

[7] Loose D, Van de Wiele C. The immune system and cancer. Cancer Biother Radiopharm 2009;24(3):369-76.

[8] Sullivan R, Alatise OI, Anderson BO, Audisio R, Autier P, Aggarwal A, et al. Global cancer surgery: Delivering safe, affordable, and timely cancer surgery. Lancet Oncol 2015;16(11):1193-224.

[9] Ellis SJ, Newland MC, Simonson JA, Peters KR, Romberger DJ, Mercer DW, et al. Anesthesia-related cardiac arrest. Anesthesiology 2014;120(4):82938.

[10] Sprung J, Warner ME, Contreras MG, Schroeder DR, Beighley CM, Wilson GA, et al. Predictors of Survival following Cardiac Arrest in Patients Undergoing Noncardiac Surgery: A Study of 518,294 Patients at a Tertiary Referral Center. Anesthesiology 2003;99(2):259-69.

[11] Fleisher LA, Fleischmann KE, Auerbach AD, Barnason SA, Beckman JA, Bozkurt B, et al. 2014 ACC/AHA guideline on perioperative cardiovascular evaluation and management of patients undergoing noncardiac surgery: A report of the American College of Cardiology/American Heart Association Task Force on practice guidelines. J Am Coll Cardiol 2014;64(22):e77-137.

[12] Kim R. Anesthetic technique and cancer recurrence in oncologic surgery: Unraveling the puzzle. Cancer Metastasis Rev 2017;36(1):159-77.

[13] Kaiser HA, Saied NN, Kokoefer AS, Saffour L, Zoller JK, Helwani MA. Incidence and prediction of intraoperative and postoperative cardiac arrest requiring cardiopulmonary resuscitation and 30-day mortality in non-cardiac surgical patients. PLoS One 2020;15(1):e0225939.

[14] Fielding-Singh V, Willingham MD, Fischer MA, Grogan T, Benharash P, Neelankavil JP. A population-based analysis of intraoperative cardiac arrest in the United States. Anesth Analg 2020;130(3):627-34.

[15] Han F, Wang Y, Wang Y, Dong J, Nie C, Chen M, et al. Intraoperative cardiac arrest: A 10-year study of patients undergoing tumorous surgery in a tertiary referral cancer center in China. Medicine (Baltimore) 2017;96(17):e6794.

[16] An JX, Zhang LM, Sullivan EA, Guo QL, Williams JP. Intraoperative cardiac arrest during anesthesia: A retrospective study of 218,274 anesthetics undergoing non-cardiac surgery. Chin Med J (Engl) 2011;124(2):227-32.

[17] Nunnally ME, O'Connor MF, Kordylewski H, Westlake B, Dutton RP. The incidence and risk factors for perioperative cardiac arrest observed in the National Anesthesia Clinical Outcomes Registry. Anesth Analg 2015;120(2):364-70.

[18] Salmasi V, Maheshwari K, Yang D, Mascha EJ, Singh A, Sessler DI, et al. Relationship between intraoperative hypotension, defined by either reduction from baseline or absolute thresholds, and acute kidney and myocardial injury after noncardiac surgery: A retrospective cohort analysis. Anesthesiology 2017;126(1):47-65.

[19] Futier E, Lefrant JY, Guinot PG, Godet T, Lorne E, Cuvillon P, et al. Effect of individualized vs standard blood pressure management strategies on postoperative organ dysfunction among high-risk patients undergoing major surgery: A randomized clinical trial. JAMA 2017;318(14):1346-57. 
[20] Wesselink EM, Kappen TH, Torn HM, Slooter AJC, van Klei WA. Intraoperative hypotension and the risk of postoperative adverse outcomes: A systematic review. Br J Anaesth 2018;121(4):706-21.

[21] Goldberger ZD, Chan PS, Berg RA, Kronick SL, Cooke CR, Lu M, et al. Duration of resuscitation efforts and survival after in-hospital cardiac arrest: An observational study. Lancet 2012;380(9852):1473-81.

[22] Welbourn C, Efstathiou N. How does the length of cardiopulmonary resuscitation affect brain damage in patients surviving cardiac arrest? A systematic review. Scand J Trauma Resusc Emerg Med 2018;26(1):77.
[23] Berek K, Jeschow M, Aichner F. The prognostication of cerebral hypoxia after out-of-hospital cardiac arrest in adults. Eur Neurol 1997;37(3):135-45.

[24] Hohn A, Machatschek JN, Franklin J, Padosch SA. Incidence and risk factors of anaesthesia-related perioperative cardiac arrest. Eur J Anaesthesiol 2018;35(4):266-72.

[25] Braz LG, Modolo NS, do Nascimento P Jr, Bruschi BA, Castiglia YM, Ganem EM, et al. Perioperative cardiac arrest: A study of 53718 anaesthetics over $9 \mathrm{yr}$ from a Brazilian teaching hospital. Br J Anaesth 2006;96(5):569-75. 